\title{
VISIÓN DE UN RESIDENTE DE CIRUGÍA
}

\section{General surgery fellow, my vision}

La seccional de residentes de Cirugía de Chile, es una organización formada el año 2013 a raíz de un interés creciente de la Sociedad de Cirujanos, por medio de su Departamento de Educación, de incluir a los futuros cirujanos del país.

Desde su creación la seccional de residentes ha logrado incluir a un porcentaje importante de residentes en formación de las 18 universidades y hospitales que imparten la especialidad a lo largo del país, sin embargo, aún existe un subregistro del número total de residentes en Chile.

Uno de los objetivos de la organización es brindar un canal de comunicación entre los residentes y permitir manifestar sus preocupaciones respecto a diversos temas; es así como en diferentes reuniones con las bases se han manifestado inquietudes de los residentes respecto a dos temas fundamentales:

En primer lugar, la Educación Médico/Quirúrgico, existiendo una preocupación creciente de los residentes respecto al aumento exponencial de cupos para la formación de especialistas sin existir en conjunto un aumento de los campos clínicos o las plazas prácticas para lograr los objetivos que la especialidad exige. Por otro lado, el estado actual de acreditación de los centros también es un tema inquietante.

Respecto al segundo punto de preocupación, este hace referencia al financiamiento de la formación de especialistas, siendo en este minuto predominantemente ministerial, esto significa que los actuales residentes tendrán un periodo de retorno a un servicio de salud definido previamente. Creemos que fomentar la actividad quirúrgica en regiones es fundamental para nuestro país, pero a su vez deben crearse las condiciones mínimas para que los profesionales puedan ejercer lo que con tanto esfuerzo y sacrificio han estudiado. Aún existe incertidumbre respecto a las condiciones laborales y asistenciales de los futuros cirujanos regidos por este sistema.

Es importante mencionar que en nuestro último registro, existen 245 residentes inscritos, de los cuales el 67,3\% tiene financiamiento ministerial, por lo tanto, con compromiso de retorno por 6 años.

Otro dato de importancia es que de los 245 residentes, 113 son de $1^{\text {er }}$ año, 74 de $2^{\circ}$ año y 58 de $3^{\text {er }}$ año; lo que nos indica el aumento exponencial de los cupos durante este último año.

Creo que la Sociedad de Cirujanos tiene un rol fundamental en fomentar una educación quirúrgica de excelencia, para ello se deben redefinir los objetivos teóricos y prácticos que requiere la formación de un cirujano. Las formas de aprendizaje en base a competencias y la simulación son herramientas que deberían ser implementadas en todos los programas de formación, sin perder jamás de vista la atención centrada en el paciente. No debemos olvidar que el fin último del quehacer médico es el paciente, su bienestar y la minimización de los riesgos para el mismo.

La necesidad de mayor cantidad de cirujanos debe en primer lugar objetivarse ¿cuántos cirujanos requiere efectivamente cada región? y en segundo lugar debe brindarse la formación adecuada a cada residente, no debemos permitir que se aumente el número en desmedro de la calidad. Nuestros pacientes merecen tener a los mejores cirujanos a su cargo.

Como presidenta saliente estoy orgullosa del trabajo desempeñado, pero a la vez entusiasta en que aún queda mucho por trabajar y mejorar, siempre en busca que los cirujanos de Chile seamos un gremio académico informado y que podamos asegurar atención de excelencia a todos los pacientes a lo largo de Chile.

Dra. Francisca González S.

Residente Cirugía General 